\title{
Store IMAgE: Scale IMPLEMENTATION Part 3
}

\author{
RONEL DU PREEZ \\ ELIZABETH VISSER \\ HESTER JANSE VAN NOORDWYK \\ Department of Industrial Psychology \\ Stellenbosch University \\ South Africa \\ Correspondence to: Ronel du Preez \\ e-mail:rdp@sun.ac.za
}

\begin{abstract}
This paper is the final in the three-part series regarding store image. The purposes of this article are to (1) implement the developed scale to assess whether it illustrates acceptable psychometric properties of reliability and validity, (2) assess the model fit of the developed scale and (3) formulate recommendations for future research. Results indicated that the Apparel Store Image Scale (ASIS) shows acceptable reliability and model fit. A refined definition of store image together with a final model of apparel store image is proposed. Recommendations for future research are made.
\end{abstract}

Keywords: store image, dimensions, apparel, conceptual model, multi-dimensional

The process of scale development comprises four phases. In the first article of this series of three, the domain of store image was delineated and an in-depth literature review culminated in a conceptual model of the store image construct (Phase 1). Building on this, the second article reported Phase 2 (generation and judging of measurement items) and Phase 3 (purification of the ASIS). In this paper the focus will turn to the implementation of the ASIS in an apparel retail environment in order to assess reliability, validity and model fit.

The purposes of this article are therefore

- to implement the ASIS to assess whether it illustrates acceptable psychometric properties of reliability and validity;

- to assess the model fit of the scale; and

- to formulate recommendations for future research

\section{ASSESSING THE SCALE - RELIABILITY AND VALIDITY (PHASE 4)}

This phase of scale development is of particular importance as the scale should display reliability, validity and usability for implementation in a retail environment. The quality of the recommendations will pivot on the quality of the measurement.

\section{Mall-intercept research method}

The mall-intercept research method was selected as this research method is frequently employed in scale development studies (Dabholkar, Thorpe \& Rentz, 1995; Dhurup, Venter \& Oosthuyzen, 2005; Parasuraman, Zeithaml \& Berry, 1988; Terblanché \& Boshoff, 2004; Venter \& Dhurup, 2005). It was deemed appropriate due to the efficiency of this method and the ease in obtaining access to a representative group of respondents (Dillon, Madden \& Firtle, 1994; Du Preez, 2001; Loudon \& Della Bitta, 1993).

\section{Sample population and sample description}

The sample population was defined as apparel consumers, both male and female, between the ages of 20 and 60, from various population groups and patronising specific apparel discount and speciality stores. A stratified quota sample $(n=534)$ was selected. This allowed for an equal respresentation of respondents regarding gender and population group.
Respondents also were equally representative of consumers of different apparel store types (discount and specialty stores) as well as location (mall and street front stores). The stores were situated in the Cape Town Metropole of the Western Cape.

Measurement instrument and data gathering

The ASIS, developed in the previous phases, was employed for data gathering (refer to article 2). The items in Section A (55 items) and Section B (eight items) remained unchanged from the previous phases. Section C, the demographics section, was adapted to include more variables. Fieldworkers were trained to assist with data gathering. Data gathering took place on Mondays to Thursdays to capture weekday shoppers, as well as Fridays and Saturdays to ensure that weekend shoppers were recruited. In addition, three time slots were identified for data gathering, namely morning, lunchtime and afternoon.

\section{Statistical analysis}

Data capturing and coding was done as per the pilot studies in the previous phase. The results from the data set $(n=534)$ were employed to assess the model fit of each of the individual dimensions, as well as the simplified model of apparel store image (see Figure 3, Part 2). Reliability was established by calculating coefficient alphas, inter-item correlation and itemtotal correlation, using Statistica (Version 8) (StatSoft Inc., 2007).

Firstly, confirmatory factor analysis (CFA) was performed on each of the individual dimensions, using LISREL (Version 8.8) (Jöreskog \& Sörbom, 2006). The method of estimation was diagonally weighted least squares (DWLS). Secondly, the measurement model was tested through CFA, using LISREL (Version 8.8) with maximum likelihood (ML) as the method of estimation. Model fit, convergent validity and discriminant validity were assessed through a combination of goodness-of-fit (GOF) measures and their associated criteria (see Table 2 in Part 2). The measurement model included store image as the exogenous latent variable. The large number of dimensions and associated measurement items of the model necessitated a sample size requirement outside of the scope of this exploratory study. Therefore, composite scores for the measurement items of each dimension were calculated into a single composite indicator (Hair, Black, Babin, Anderson \& Tatham, 2006; Netemeyer, Bearden \& Sharma, 2003). This was deemed appropriate since the CFAs performed on each of the 
individual dimensions allowed for individual item analysis, whilst the CFA performed on the simplified model of appare store image allowed for assessing the total model fit. Thus, the dimensions (as per the simplified model of apparel store image) were identified as indicator variables.

\section{RESULTS AND DISCUSSION}

\section{Sample profile}

Table 1 provides a summary of the demographic characteristics of the sample population.

TABLE 1

Demographic profile of respondents - Mall intercept study

\begin{tabular}{|c|c|c|c|}
\hline VARIABLES & CATEGORIES & $\mathbf{n}$ & $\%$ \\
\hline \multirow[t]{2}{*}{ Gender $(n=531)$} & Male & 265 & 49.91 \\
\hline & Female & 266 & 50.09 \\
\hline \multirow[t]{6}{*}{ Age $(n=533)$} & $<20$ & 52 & 9.76 \\
\hline & $20-29$ & 249 & 46.72 \\
\hline & $30-39$ & 121 & 22.70 \\
\hline & $40-49$ & 56 & 10.51 \\
\hline & $50-59$ & 39 & 7.32 \\
\hline & $>60$ & 16 & 3.00 \\
\hline \multirow[t]{3}{*}{ Population group $(n=528)$} & Black & 174 & 32.95 \\
\hline & Coloured & 181 & 34.28 \\
\hline & White & 170 & 32.20 \\
\hline \multirow[t]{3}{*}{ Home language $(n=514)$} & Afrikaans & 236 & 45.91 \\
\hline & English & 112 & 21.79 \\
\hline & Other & 166 & 32.3 \\
\hline \multirow[t]{5}{*}{ Marital status $(n=523)$} & Cohabitating/living together & 18 & 3.44 \\
\hline & Married & 171 & 32.60 \\
\hline & Not married & 302 & 57.74 \\
\hline & Divorced/separated & 20 & 3.82 \\
\hline & Widow/widower & 12 & 2.29 \\
\hline \multirow[t]{8}{*}{ Job description $(n=534)$} & Unemployed & 59 & 11.05 \\
\hline & $\begin{array}{l}\text { Clerical, salesperson, } \\
\text { technician, secretarial }\end{array}$ & 127 & 23.78 \\
\hline & $\begin{array}{l}\text { Middle management (teacher, } \\
\text { nursing sister) }\end{array}$ & 57 & 10.67 \\
\hline & Corporate (manager) & 20 & 3.75 \\
\hline & Professional (doctor, director) & 25 & 4.68 \\
\hline & Homemaker & 28 & 5.24 \\
\hline & Retired & 15 & 2.81 \\
\hline & Other & 203 & 38.01 \\
\hline \multirow[t]{9}{*}{ Monthly income $(n=526)$} & $<$ R500 & 42 & 7.98 \\
\hline & R501-R1 000 & 44 & 8.37 \\
\hline & R1 001-R3 000 & 106 & 20.15 \\
\hline & R3 001-R5 000 & 76 & 14.45 \\
\hline & R5 001-R7 000 & 75 & 14.26 \\
\hline & R7 001-R10 000 & 54 & 10.27 \\
\hline & R10 001-R20 000 & 77 & 14.64 \\
\hline & R20 001-R30 000 & 24 & 4.56 \\
\hline & $>\mathrm{R} 30000$ & 28 & 5.43 \\
\hline \multirow{7}{*}{$\begin{array}{l}\text { How often you buy } \\
\text { clothes? }(n=533)\end{array}$} & When needed & 178 & 33.40 \\
\hline & Once a year & 13 & 2.44 \\
\hline & Twice a year & 28 & 5.25 \\
\hline & Three times a year & 34 & 6.38 \\
\hline & Monthly & 199 & 37.34 \\
\hline & Weekly & 57 & 10.69 \\
\hline & Other & 24 & 4.50 \\
\hline \multirow{7}{*}{$\begin{array}{l}\text { Average monthly spending } \\
\text { on clothes }(n=529)\end{array}$} & $<$ R99 & 33 & 6.24 \\
\hline & R100-R199 & 52 & 9.83 \\
\hline & R200-R299 & 93 & 17.58 \\
\hline & R300-R399 & 77 & 14.56 \\
\hline & R400-R499 & 61 & 11.53 \\
\hline & R500-R599 & 68 & 12.85 \\
\hline & $>\mathrm{R} 600$ & 145 & 27.41 \\
\hline
\end{tabular}

TABLE 2

Reliability and item-total correlations - Mall intercept stud

\begin{tabular}{|c|c|c|c|c|c|c|}
\hline CONSTRUCT & DIMENSIONS & $\underset{\underset{E}{E}}{\sum}$ & 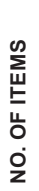 & 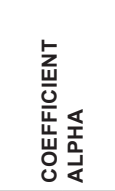 & 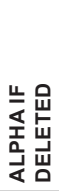 & 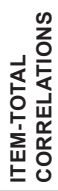 \\
\hline \multirow[t]{64}{*}{ Store image } & & & 55 & 0.83 & & \\
\hline & Atmosphere & & 6 & 0.68 & & \\
\hline & & 1 & & & 0.62 & 0.43 \\
\hline & & 2 & & & 0.60 & 0.51 \\
\hline & & 3 & & & 0.60 & 0.52 \\
\hline & & 4 & & & 0.65 & 0.37 \\
\hline & & 5 & & & 0.64 & 0.41 \\
\hline & & 6 & & & 0.69 & 0.22 \\
\hline & Convenience & & 7 & 0.69 & & \\
\hline & & 7 & & & 0.66 & 0.40 \\
\hline & & 8 & & & 0.66 & 0.40 \\
\hline & & 9 & & & 0.65 & 0.42 \\
\hline & & 10 & & & 0.66 & 0.41 \\
\hline & & 11 & & & 0.64 & 0.48 \\
\hline & & 12 & & & 0.68 & 0.32 \\
\hline & & 13 & & & 0.67 & 0.38 \\
\hline & Facilities & & 7 & 0.77 & & \\
\hline & & 14 & & & 0.75 & 0.47 \\
\hline & & 15 & & & 0.74 & 0.52 \\
\hline & & 16 & & & 0.73 & 0.55 \\
\hline & & 17 & & & 0.74 & 0.50 \\
\hline & & 18 & & & 0.75 & 0.44 \\
\hline & & 19 & & & 0.73 & 0.53 \\
\hline & & 20 & & & 0.76 & 0.42 \\
\hline & Institutional & & 6 & 0.72 & & \\
\hline & & 21 & & & 0.70 & 0.40 \\
\hline & & 22 & & & 0.65 & 0.57 \\
\hline & & 23 & & & 0.69 & 0.46 \\
\hline & & 24 & & & 0.68 & 0.49 \\
\hline & & 25 & & & 0.67 & 0.52 \\
\hline & & 26 & & & 0.72 & 0.32 \\
\hline & Merchandise & & 8 & 0.77 & & \\
\hline & & 27 & & & 0.76 & 0.34 \\
\hline & & 28 & & & 0.74 & 0.48 \\
\hline & & 29 & & & 0.73 & 0.54 \\
\hline & & 30 & & & 0.72 & 0.56 \\
\hline & & 31 & & & 0.72 & 0.56 \\
\hline & & 32 & & & 0.73 & 0.50 \\
\hline & & 33 & & & 0.75 & 0.40 \\
\hline & & 34 & & & 0.76 & 0.37 \\
\hline & Promotion & & 8 & 0.78 & & \\
\hline & & 35 & & & 0.77 & 0.40 \\
\hline & & 36 & & & 0.77 & 0.46 \\
\hline & & 37 & & & 0.76 & 0.50 \\
\hline & & 38 & & & 0.76 & 0.47 \\
\hline & & 39 & & & 0.75 & 0.55 \\
\hline & & 40 & & & 0.76 & 0.50 \\
\hline & & 41 & & & 0.75 & 0.57 \\
\hline & & 42 & & & 0.76 & 0.48 \\
\hline & Sales personnel & & 5 & 0.79 & & \\
\hline & & 43 & & & 0.79 & 0.43 \\
\hline & & 44 & & & 0.77 & 0.52 \\
\hline & & 45 & & & 0.72 & 0.65 \\
\hline & & 46 & & & 0.73 & 0.63 \\
\hline & & 47 & & & 0.73 & 0.62 \\
\hline & Service & & 8 & 0.73 & & \\
\hline & & 48 & & & 0.72 & 0.33 \\
\hline & & 49 & & & 0.73 & 0.26 \\
\hline & & 50 & & & 0.72 & 0.30 \\
\hline & & 51 & & & 0.67 & 0.56 \\
\hline & & 52 & & & 0.68 & 0.51 \\
\hline & & 53 & & & 0.70 & 0.45 \\
\hline & & 54 & & & 0.69 & 0.47 \\
\hline & & 55 & & & 0.69 & 0.50 \\
\hline
\end{tabular}

Values not meeting the criteria are highlighted 


\section{Reliability}

The coefficient alpha for the total scale was recorded at 0.83 , whilst values for the individual dimensions ranged from 0.68 to 0.79 as presented in Table 2. The Atmosphere $(\alpha=0.68)$ and Convenience $(\alpha=0.69)$ dimensions did not meet the set criteria for alpha $>0.7$. All inter-item correlations were within the set parameters of 0.2-0.5. The item-total correlations of 0.22 for item 6 (shopping experience) and 0.26 for item 49 (courteousness of sales personnel) did not meet the adopted cut-off value of $>0.3$ and could negatively influence scale reliability.

\section{Model fit - individual dimensions}

CFA employing DWLS as method of estimation was performed separately on each of the dimensions. The indices of model fit are summarised in Table 3. The significant normal theory weighted least square chi-square statistics for all the dimensions are indicative of a significant discrepancy between the covariance matrix of the implied and observed model, thereby suggesting poor model fit. However, caution should be taken when interpreting the chi-square statistic, since it is sensitive to multivariate normality and sample size (Diamantopoulos \& Sigauw, 2000).

The examination of the various model fit indices led to the conclusion that the Atmosphere, Convenience and Institutional dimensions exhibited good fit. The Promotion dimension also demonstrated good fit, except for the standardised root mean residual (RMR) value that fell marginally outside of the proposed fit criterion. The absolute fit measures, apart from the goodness-of-fit index (GFI) and adjusted goodness-of-fit index (AGFI) measures, for the Facilities and Sales personnel dimensions indicated poor fit, although the incremental fit indices supported good fit. It could be argued that these models show at least acceptable fit. Lastly, the absolute fit measures, except for the GFI and AGFI indices for Merchandise and Service, suggested poor fit, which is further supported by one of the incremental fit indices, namely, the non-normed fit index (NNFI). However, all other incremental fit indices presented a good fit. Thus, the model fit on these dimensions can be considered as marginally acceptable.

To identify problematic measurement items the deletion of which could contribute to improved model fit for each of the dimensions, the path estimates, standardised residuals, variance extracted (VE) and criterion reliability (CR) were considered according to the set criteria (refer to Table 4). The literature cautioned, however, that individual items should only be considered for deletion if their deletion can be justified theoretically (Hair et al., 2006). Therefore, the results for each dimension were considered in conjunction with results from previous store image research. Table 4 depicts the completely standardised loadings, VE and CR of all the dimensions. The criteria will be used in conjunction with the literature to decide upon the deletion or retention of items. Values not meeting the criteria are highlighted.
Atmosphere: The deletion of item 6 is supported by its itemtotal correlation (0.22). All the standardised residuals for this dimension met the set criteria (see Table 5). The CFA results supported the retention of items 1 to 5 and were consistent with previous research findings associating these items with the Atmosphere dimension (Janse van Noordwyk, 2002; Kotler, 1973-1974; Moye \& Kincade, 2002; Thang \& Tan, 2003). The empirical results of this study indicated that item 6 (relating to shopping experience) should be considered for deletion. This is inconsistent with findings from previous research (Janse van Noordwyk, 2002; Kim \& Jin, 2001). However, Terblanché and Boshoff (2004) developed a generic instrument to measure consumer satisfaction with the controllable elements of the instore shopping experience. Their results indicated that shopping experience is a function not only of the internal store environment but also of merchandise value, personal interaction, merchandise variety and complaint handling. Results from Kleinhans (2003) showed that shopping experience was associated with Sales personnel service. It could be deduced that shopping experience is associated with the store atmosphere but not exclusively so. Thus, results from these studies suggested that this item might be associated with more than one store image dimension. It should, therefore, be considered for deletion from the Atmosphere dimension.

Convenience: The standardised residuals (see Table 6) between items 9 and 10 (2.93) and items 8 and 12 (2.89) fell outside of the $|2.5|$ criterion. However, they did not exceed the $|4|$ criterion and should be retained, since there is no evidence from the completely standardised loadings to suggest their deletion.

The retention of all items in the Convenience dimension was supported by previous store image research focussing on item-specific content (Bellenger, Robertson \& Greenberg, 1977; Chowdhary, 1999; Hansen \& Deutscher, 1977-1978; Huddleston, Ford \& Mahoney, 1990; Janse van Noordwyk, 2002; Kim \& Jin, 2001; Kleinhans, 2003; Lumpkin, Greenberg \& Goldstucker, 1985; Marks, 1976; Sullivan, Savitt, Zheng \& Cui, 2002; Thang \& Tan, 2003; Wong \& Teas, 2001).

Facilities: All of the scale items had completely standardised loadings $>0.5$, suggesting that all items should be retained. However, VE was calculated at 0.39 . High standardised residuals (SR) between items is presented in Table 7. The SR between items 18 and 19 (9.40) and items 15 and 16 (7.05) exceeded the $|4|$ criterion. Item 15 also shared high SR, although not exceeding $|4|$, with items $18(-3.91)$ and $19(-3.50)$, as did item 19 with items $15(-3.50)$ and $16(-2.59)$. This suggested that items 15 and 19 should be considered for deletion based on their high residual values. The SR between items 17 and 20 (2.61) exceeded the $|2.5|$ criterion, but no other evidence suggested the deletion of these items and they should, therefore, be retained.

Janse van Noordwyk (2002) included store appearance (item 14) and fixtures (item 17) within the Facilities dimension. Kleinhans (2003) as well as Wong and Teas (2003) corroborated

TABLE 3

Model fit indices of CFA on individual dimensions - Mall intercept study

\begin{tabular}{|c|c|c|c|c|c|c|c|c|}
\hline MODEL FIT INDICES & ATMOSPHERE & E CONVENIENCE & FACILITIES & INSTITUTIONAL & MERCHANDISE & PROMOTION & $\begin{array}{l}\text { SALES } \\
\text { PERSONNEL }\end{array}$ & SERVICE \\
\hline \multicolumn{9}{|l|}{ Absolute Fit Measure } \\
\hline Degrees of Freedom & & 14 & 14 & 9 & 20 & 20 & 5 & 20 \\
\hline Normal Theory Weighted Least Square Chi-Square & $\begin{array}{r}26.95 \\
p<0.0\end{array}$ & $\begin{array}{r}79.96 \\
p<0.01\end{array}$ & $\begin{array}{r}373.85 \\
p<0.01\end{array}$ & $\begin{array}{r}75.56 \\
p<0.01\end{array}$ & $\begin{array}{r}826.27 \\
p<0.01\end{array}$ & $\begin{array}{r}181.93 \\
p<0.01\end{array}$ & $\begin{array}{r}153.13 \\
p<0.01\end{array}$ & $\begin{array}{r}626.00 \\
p<0.01\end{array}$ \\
\hline Root Mean Square Error of Approximation (RMSEA) & $0.02 C$ & 0.057 & 0.13 & 0.073 & 0.15 & 0.063 & 0.15 & 0.14 \\
\hline Standardised Root Mean Residual (RMR) & 0.03 & 0.050 & 0.094 & 0.050 & 0.13 & 0.062 & 0.071 & 0.13 \\
\hline Goodness of Fit Index (GFI) & 1.00 & 0.99 & 0.97 & 0.99 & 0.95 & 0.99 & 0.99 & 0.95 \\
\hline Adjusted Goodness of Fit (AGFI) & 0.95 & 0.98 & 0.93 & 0.98 & 0.91 & 0.98 & 0.96 & 0.91 \\
\hline \multicolumn{9}{|l|}{ Incremental Fit Measures } \\
\hline Non-Normed Fit Index (NNFI) & 1.00 & 0.98 & 0.92 & 0.98 & 0.89 & 0.99 & 0.95 & 0.89 \\
\hline Comparative Fit Index (CFI) & 1.00 & 0.99 & 0.95 & 0.99 & 0.92 & 0.99 & 0.97 & 0.92 \\
\hline
\end{tabular}


the association of store appearance with the Facilities dimension. Results from Kim and Jin (2001) and Sullivan et al. (2002) supported the inclusion of convenience of facilities (item 20) in the Facilities dimension.

The deletion of items 15 and 19, as suggested by the CFA results, should be considered in conjunction with the retention of items 16 and 18. Items 15 and 16 relate to the position and width of the aisles in the store respectively. Previous store image research also identified layout as underpinning the Facilities dimension (Hansen \& Deutscher, 1977-1978; Janse van Noordwyk, 2002; Lindquist, 1974-1975; Wong \& Yu, 2003). To operationalise layout, items were included to measure both the position and width of the aisles based on previous store image research (Kim \& Jin, 2001; Kleinhans, 2003). Similarly, items 18 and 19 referred to the number of and lighting in the fitting rooms respectively. Fitting rooms were identified as a subdimension of Facilities based on previous research on consumer expectations for service at apparel retail outlets (Lee \& Johnson, 1997), the large-size female apparel consumer (Janse van Noordwyk, 2002) and consumer perception and preference regarding department stores (Thang \& Tan, 2003). According to Kleinhans (2003), store layout was operationalised through items 18 and 19. However, results suggested that aisle width (item 16) and number of fitting rooms (item 18) were better measures of store layout and fitting rooms. Therefore, there were no theoretical objections to the deletion of aisle position (item 15) and lighting in fitting rooms (item 19).

Institutional: Item 26 (0.41) should be considered for deletion. The SR (Table 4.16) between items 24 and 25 (4.11) exceeded the cut-off value of $|4|$, but only marginally. No other evidence supports the deletion of either of these items, thus suggesting that these items should be retained for further testing. Similarly, the SR between items 21 and 22 (2.90) exceeded the $|2.5|$ criteria but with no other evidence to suggest deletion.

Previous research supports the retention of items 21 to 25 (Hansen \& Deutscher, 1977-1978; Janse van Noordwyk, 2002; Lindquist, 1974-1975). Item 26, relating to the store's efforts to build a personal relationship with customers (e.g. personalised letters), was derived from research done by Janse van Noordwyk (2002). CFA results support the deletion of this item. Since this item appears in only one isolated research finding, it is not substantial enough to warrant its retention, and this item should thus be considered for deletion.

Merchandise: Based on the completely standardised loading of item $27(0.46)$ as well as the VE of 0.4, this item should be considered for deletion. The CR was 0.84 . The standardised residuals, as presented by Table 4.17 , between items 33 and 34 (10.34), items 29 and 30 (10.22), items 28 and 31 (4.58) and items 30 and $33(-4.01)$ fell outside the set criterion of $<|4|$. Items 30 and 33 are associated with more than one of these high standardised residuals. Item 30 further shared high standardised residuals with item 32 (-3.42) and item 34 (-2.87), suggesting that it should be considered for deletion. Similarly, item 33 also shared standardised residuals higher than $|2.5|$ with items $29(-3.87)$ and item 27 (2.63). This suggests that items 30 and 33 should be considered for deletion.

The literature suggested that only one item from a pair sharing a high residual should be dropped (Hair et al., 2006). Therefore, although item 29 (associated with a high residual with item 30) and item 34 (associated with a high residual with item 33) share high standardised residuals with other items, these do not exceed $|4|$. Item 34 is associated with high standardised residuals for items 28 to 31 and 33 . There is no other support for deleting items 29 and 34 and they should therefore be retained. Lastly, the SR between items 31 and 32 (3.54) and items 28 and 34 $(-3.29)$ both exceed the $|2.5|$ criterion, but no further evidence supports the deletion of these items. Since the standardised residual does not exceed $|4|$, these items should be retained.
TABLE 4

Summary: Completely standardised loadings, VE and CR - Mall Intercept study

\begin{tabular}{|c|c|c|c|c|}
\hline \multirow[b]{3}{*}{ Dimension } & \multicolumn{4}{|c|}{$\begin{array}{l}\text { CRITERIA FOR DELETION OF ITEMS AND } \\
\text { EVALUATION OF DIMENSIONS }\end{array}$} \\
\hline & & $<0.5$ & $<0.5$ & $<0.7$ \\
\hline & $\begin{array}{l}\text { Item } \\
\text { number }\end{array}$ & $\begin{array}{l}\text { Completely } \\
\text { Standardised } \\
\text { Loading }\end{array}$ & $\begin{array}{l}\text { Variance } \\
\text { Extracted } \\
\text { (VE) }\end{array}$ & $\begin{array}{l}\text { Construct } \\
\text { Reliability } \\
\text { (CR) }\end{array}$ \\
\hline \multirow[t]{7}{*}{ Atmosphere } & & & 0.37 & 0.77 \\
\hline & 1 & 0.64 & & \\
\hline & 2 & 0.77 & & \\
\hline & 3 & 0.75 & & \\
\hline & 4 & 0.53 & & \\
\hline & 5 & 0.52 & & \\
\hline & 6 & 0.33 & & \\
\hline \multirow[t]{8}{*}{ Convenience } & & & 0.32 & 0.77 \\
\hline & 7 & 0.52 & & \\
\hline & 8 & 0.57 & & \\
\hline & 9 & 0.60 & & \\
\hline & 10 & 0.60 & & \\
\hline & 11 & 0.62 & & \\
\hline & 12 & 0.50 & & \\
\hline & 13 & 0.55 & & \\
\hline \multirow[t]{8}{*}{ Facilities } & & & 0.39 & 0.82 \\
\hline & 14 & 0.61 & & \\
\hline & 15 & 0.65 & & \\
\hline & 16 & 0.73 & & \\
\hline & 17 & 0.60 & & \\
\hline & 18 & 0.59 & & \\
\hline & 19 & 0.67 & & \\
\hline & 20 & 0.52 & & \\
\hline \multirow[t]{7}{*}{ Institutional } & & & 0.35 & 0.76 \\
\hline & 21 & 0.50 & & \\
\hline & 22 & 0.73 & & \\
\hline & 23 & 0.56 & & \\
\hline & 24 & 0.63 & & \\
\hline & 25 & 0.66 & & \\
\hline & 26 & 0.41 & & \\
\hline \multirow[t]{9}{*}{ Merchandise } & & & 0.40 & 0.84 \\
\hline & 27 & 0.46 & & \\
\hline & 28 & 0.58 & & \\
\hline & 29 & 0.73 & & \\
\hline & 30 & 0.73 & & \\
\hline & 31 & 0.70 & & \\
\hline & 32 & 0.62 & & \\
\hline & 33 & 0.57 & & \\
\hline & 34 & 0.50 & & \\
\hline \multirow[t]{9}{*}{ Promotion } & & & 0.38 & 0.83 \\
\hline & 35 & 0.50 & & \\
\hline & 36 & 0.56 & & \\
\hline & 37 & 0.58 & & \\
\hline & 38 & 0.58 & & \\
\hline & 39 & 0.69 & & \\
\hline & 40 & 0.62 & & \\
\hline & 41 & 0.69 & & \\
\hline & 42 & 0.63 & & \\
\hline \multirow[t]{6}{*}{ Sales Personnel } & & & 0.52 & 0.84 \\
\hline & 43 & 0.53 & & \\
\hline & 44 & 0.65 & & \\
\hline & 45 & 0.78 & & \\
\hline & 46 & 0.79 & & \\
\hline & 47 & 0.80 & & \\
\hline \multirow[t]{9}{*}{ Service } & & & 0.34 & 0.80 \\
\hline & 48 & 0.48 & & \\
\hline & 49 & 0.41 & & \\
\hline & 50 & 0.42 & & \\
\hline & 51 & 0.72 & & \\
\hline & 52 & 0.64 & & \\
\hline & 53 & 0.61 & & \\
\hline & 54 & 0.64 & & \\
\hline & 55 & 0.64 & & \\
\hline
\end{tabular}


TABLE 5

Standardised residuals for Atmosphere dimension - Mall intercept study

\begin{tabular}{lrrrrrr}
\hline ITEM & Item 1 & Item 2 & Item 3 & Item 4 & Item 5 & Item 6 \\
\hline Item 1 & - & & & & & \\
Item 2 & 0.37 & - & & & & \\
Item 3 & -1.01 & 1.27 & - & & & \\
Item 4 & 1.01 & -1.48 & 0.10 & - & & \\
Item 5 & -0.67 & -0.69 & 0.10 & 1.11 & - & \\
Item 6 & 0.70 & 0.36 & -0.93 & -0.90 & 0.76 & - \\
\hline
\end{tabular}

TABLE 6

Standardised residuals for Convenience dimension - Mall intercept study

\begin{tabular}{lrrrrrrr}
\hline ITEM & Item 7 & Item 8 & Item 9 & Item 10 & Item 11 & Item 12 & Item 13 \\
\hline Item 7 & - & & & & & & \\
Item 8 & -0.08 & - & & & & & \\
Item 9 & -0.97 & -1.06 & - & & & & \\
Item 10 & 0.51 & -0.47 & $\mathbf{2 . 9 3}$ & - & & & \\
Item 11 & 2.06 & -0.77 & 0.63 & -0.09 & - & & \\
Item 12 & 0.08 & $\mathbf{2 . 8 9}$ & -1.14 & -1.85 & -2.02 & - & \\
Item 13 & -0.81 & -0.20 & -0.87 & -0.33 & 0.02 & 2.37 & - \\
\hline
\end{tabular}

TABLE 7

Standardised residuals for Facilities dimension - Mall intercept study

\begin{tabular}{lrrrrrrr}
\hline ITEMS & Item 14 & Item 15 & Item 16 & Item 17 & Item 18 & Item 19 & Item 20 \\
\hline Item 14 & - & & & & & & \\
Item 15 & -0.25 & - & & & & & \\
Item 16 & -0.32 & $\mathbf{7 . 0 5}$ & - & & & & \\
Item 17 & -0.66 & 0.88 & 0.21 & - & & & \\
Item 18 & -0.08 & $-\mathbf{- 3 . 9 1}$ & -2.48 & -1.03 & - & & \\
Item 19 & -0.22 & $\mathbf{- 3 . 5 0}$ & $\mathbf{- 2 . 5 9}$ & -1.86 & $\mathbf{9 . 4 0}$ & - & \\
Item 20 & 1.76 & -0.38 & -1.98 & $\mathbf{2 . 6 1}$ & -1.86 & -0.08 & \\
\hline
\end{tabular}

The retention of items $28,29,31,32$, and 34 as supported by the CFA results confirms findings from the literature (Marks, 1976; Wong \& Yu, 2003).

Odekerken-Schröder, De Wulf, Kasper, Kleijnen, Hoekstra and Commandeur (2001) as well as Koo (2003) confirmed that merchandise assortment (item 31) is associated with the Merchandise dimension. Cary and Zylla (1981) investigated fabric speciality store consumers' dissatisfaction with selected in-store attributes. They supported the inclusion of style (item 32) within the Merchandise dimension. Bellenger et al. (1977), Bellizzi, Crowley and Hasty (1983), as well as Wong and Teas (2001) determined through exploratory factor analysis that quality (item 34) is associated with Merchandise.

Based on the underlying structure of store image proposed in this series, items 28,30 and 33 were included in the Merchandise dimension. Chowdhary (1999) investigated the apparel shopping behaviour of elderly men and women and included item 28 to measure the importance of the availability of imported merchandise. The CFA results support the inclusion of this item in the Merchandise dimension. Item 30, relating to the availability of exclusive merchandise (e.g. limited number manufactured), and item 33 , relating to the availability of styles suited to my age, were included in a study by Thompson and Chen (1998), following a means-end approach to retail store image. The results from this paper/study do not support their inclusion within Merchandise. Since their inclusion was based on isolated research findings, there is no substantial evidence in support of their retention. Thus, these items (30 and 33) should be considered for deletion.

The results further support the deletion of item 27 associated with merchandise assortment. However, various store image studies support the inclusion of this item within the Merchandise dimension (Bellizzi et al., 1983; Cary \& Zylla, 1981; Ko \& Kincade, 1997; Koo, 2003; Odekerken-Schröder et al., 2001; Sullivan et al., 2002; Terblanché \& Boshoff, 2004; Wong \& Yu,
TABLE 8

Standardised residuals for Institutional dimension - Mall intercept study

\begin{tabular}{lrrrrrr}
\hline ITEMS & Item 21 & Item 22 & Item 23 & Item 24 & Item 25 & Item 26 \\
\hline Item 21 & - & & & & & \\
Item 22 & $\mathbf{2 . 9 0}$ & - & & & & \\
Item 23 & 0.49 & 1.18 & - & & & \\
Item 24 & -0.71 & -2.50 & -0.34 & - & & \\
Item 25 & -1.67 & -0.49 & -2.09 & $\mathbf{4 . 1 1}$ & - & \\
Item 26 & -1.56 & -0.39 & 1.28 & 0.11 & 0.50 & - \\
\hline
\end{tabular}

\section{TABLE 9}

Standardised residuals for Merchandise dimension - Mall intercept study

\begin{tabular}{|c|c|c|c|c|c|c|c|c|}
\hline ITEMS & Item 27 & Item 28 & Item 29 & Item 30 & Item 31 & Item 32 & Item 33 & 3 Item 34 \\
\hline Item 27 & - & & & & & & & \\
\hline Item 28 & -1.91 & - & & & & & & \\
\hline Item 29 & -0.58 & 0.88 & - & & & & & \\
\hline Item 30 & -1.26 & 0.00 & 10.22 & - & & & & \\
\hline Item 31 & -1.86 & 4.58 & -1.92 & -0.78 & - & & & \\
\hline Item 32 & 2.31 & -0.71 & -3.21 & -3.42 & 3.54 & - & & \\
\hline Item 33 & 2.63 & -2.00 & -3.87 & -4.01 & -2.27 & 2.55 & & - \\
\hline Item 34 & 2.19 & -3.29 & -3.46 & -2.87 & -2.78 & 0.81 & 10.34 & \\
\hline
\end{tabular}

TABLE 10

Standardised residuals for Promotion dimension - Mall intercept study

\begin{tabular}{|c|c|c|c|c|c|c|c|c|}
\hline ITEMS & Item 35 & Item 36 & Item 37 & Item 38 & Item 39 & Item 40 & Item 41 & Item 42 \\
\hline Item 35 & - & & & & & & & \\
\hline Item 36 & 0.41 & - & & & & & & \\
\hline Item 37 & 0.35 & 2.14 & - & & & & & \\
\hline Item 38 & 0.30 & 0.33 & 1.07 & - & & & & \\
\hline Item 39 & -0.57 & 1.25 & -0.44 & 0.81 & - & & & \\
\hline Item 40 & -0.53 & -0.32 & -0.67 & -1.68 & -0.22 & - & & \\
\hline Item41 & 0.92 & -2.09 & -1.00 & -1.46 & -0.05 & 1.68 & - & \\
\hline Item 42 & -1.02 & -1.93 & -1.39 & 0.70 & -0.90 & 2.29 & 2.64 & \\
\hline
\end{tabular}

2003). Based on the substantial theoretical evidence for the retention of this item in the Merchandise dimension, it should be retained.

Promotion: All the completely standardised loadings exceeded the 0.5 cut-off value. Table 10 presents the standardised residuals for the Promotion dimension. Only one SR was higher than $|2.5|$, namely between items 41 and 42 (2.64), but with no evidence to suggest the deletion of either item.

Previous store image research supported the results from this study for the retention of all measurement items. Lindquist (1974-1975) first proposed the inclusion of advertising (item 35), displays (items 38 and 39) and sales incentives (item 40) in the Promotion dimension. This was supported by Janse van Noordwyk's (2002) findings that associate advertising (items 35 , 36 and 37), displays (items 38 and 39) and sales incentives (items 40, 41 and 42) with Promotion. Wong and Yu (2003) provided support for advertising (item 35) and sales incentives (item 40) being associated with the Promotion dimension. Kleinhans (2003) included displays (items 38 and 39) and sales incentives (items 40, 41 and 42) in this dimension. Findings by Hansen and Deutscher (1977-1978), Marks (1976) and Thang and Tan (2003) further corroborated that advertising (item 35) should be included in Promotion. Lastly, Wong and Teas (2001) found that sales incentives (item 40) were associated with the Promotion dimension.

Sales personnel: None of the completely standardised loadings was below the 0.5 criterion as presented in Table 4 . Both the VE (0.52) and CR (0.84) met the cut-off values of $>0.5$ and $>0.7$ respectively. The standardised residuals, presented in Table 11, between items 46 and 47 (6.76) and items 43 and 44 (4.70) exceeded the $|4|$ cut-off value. Item 47 shared a residual of -2.58 with item 43 , whilst items 44 and 46 shared a residual of -3.32. Deleting more than one item from this dimension would 
result in fewer than four items for this dimension, resulting in underidentification. Therefore, based on the comparatively low standardised loading of item 43 (0.53), only this item could be considered for deletion. This is in accordance with recommendations in the literature suggesting that, if necessary, a poor-performing item should be retained to satisfy statistical identification requirements or to meet the minimum number of items necessary per factor consideration (Hair et al., 2006).

The retention of items 46 and 47, as suggested by the CFA results, are supported by results from Kleinhans (2003). Joyce and Lambert (1996) examined the impact of age on consumers' perception of retail store image. Their study did not focus on the underlying structure of store image but included individual items associated with store image. Item 44 (attractiveness of sales personnel) and item 45 (similarity in body type between sales personnel and myself) were derived from their study. The CFA results confirmed that these items should be included in the Sales personnel dimension and support their retention. However, the results from the current study do not provide support for Kleinhans' (2003) finding that item 43 should be retained within the Sales personnel dimension. Based on the isolated theoretical support for the inclusion of this item, it should be considered for deletion

Service: The completely standardised loadings of items 48 (0.48), 49 (0.41) and 50 (0.42) were all less than 0.50 and should be considered for deletion. The deletion of item 49 was further supported by its item-total correlation (0.26) being less than the set criterion of $>0.3$. VE did not meet the set cut-off value of $>0.5$ and was recorded at 0.34 . The CR of 0.80 met the set criterion of $>0.7$. The shared standardised residuals (Table 12) between items 48 and 49 (6.55), items 48 and 50 (5.75) and items 48 and 54 $(-4.18)$ all exceeded $|4|$. In addition, the standardised residuals between items 49 and $52(-3.80)$, items 49 and $54(-3.53)$, items 49 and 50 (3.06), items 50 and 54 (-3.00) and items 49 and 53 (2.75) exceeded the $|2.5|$ criterion. This supports the evidence from the standardised loadings, suggesting that items 48,49 and 50 should be deleted. The standardised residuals between items 51 and 52 (3.98), items 54 and 55 (3.41) and items 52 and 54 (3.12) were higher than the $|2.5|$ cut-off value. However, no other evidence suggests their deletion and they should therefore be retained.

The CFA results supporting the retention of items 52, 53 and 55 confirmed evidence from previous store image research Support for delivery options, but not specifically mail order can also be found in store image research (Grace \& O'Cass, 2005; Ko \& Kincade, 1997; Thang \& Tan, 2003). The inclusion of item 55, associated with after-sales service, within the Service dimension was confirmed by Erdem, Oumlil and Tuncalp (1999), as well as Lee and Johnson (1997). Item 51 (availability of gift vouchers), relating to in-store service, was specific to the current study and its inclusion in Service is confirmed by the CFA results. Items 48,49 and 50 , all specific to sales personnel instore service, were not supported by the results of this study. In the review of the literature, various overlaps occurred between the Sales personnel and Service dimensions. Based on this, the Sales personnel interaction subdimension (including items 48 , 49 and 50) was included within the Service dimension after pilot study 1 . However, the CFA results from this phase of the study suggested that these items should not have been included in the Service dimension, even though findings from previous research indicated that items 48 and 49 should be included in a store image scale (Grace \& O'Cass, 2005; Kleinhans, 2003; Koo, 2003; Lee \& Johnson, 1997; Marks, 1976; Odekerken-Schröder et al., 2001; Terblanché \& Boshoff, 2004).

Empirical findings from specific studies provide evidence that Sales personnel service is a dimension distinct from Service. Lee and Johnson (1997) distinguished between dimensions of service - store amenities, service - store facilities, and service - sales associates' attributes in their qualitative study. Kleinhans (2003) identified salespersons'service and variousstoreservices dimensions through EFA. CFA confirmed two distinct dimensions, namely employee service and after-sales service, in a study on the interrelationships between store images, store satisfaction and store loyalty amongst Korean discount retail consumers (Koo, 2003). Lastly, Grace and O'Cass (2005) confirmed a model postulating that store service provision consists of core service, employee service and servicescape. Although not all research supports this distinction (Hansen \& Deutscher, 1977-1978; Janse van Noordwyk, 2002; Lindquist, 1974-1975), there is substantial theoretical evidence that these items should be retained. Based on previous research findings, it could be suggested that the items be included in a distinct dimension incorporating sales personnel service.

Item 50 was specific to this study and there is no theoretical support for its retention. However, should a separate dimension for sales personnel service be included, it will be underidentified for CFA by only two items. Item 50 should therefore be retained and items previously deleted should be considered to ensure that the proposed sales personnel service dimension is identified for CFA with a minimum of four items

\section{Convergent and discriminant validity - individual dimensions}

Completely standardised loadings, VE and CR were considered to assess the convergent and discriminant validity of the store image scale. Completely standardised loadings of $>0.5, \mathrm{VE}$ of $>0.5$ and CR of $>0.7$ were used as criteria for establishing convergent validity as per recommendations in the literature (Hair et al., 2006). Items with completely standardised loadings of less than 0.5 have already been identified for the following dimensions, namely Atmosphere (item 6), Institutional (item 26), Merchandise (item 27) and Service (items 48, 49 and 50). Based on this, the first criterion for convergent validity was not met by these dimensions. The VE for each dimension shows that none of the dimensions, except for Sales personnel (0.52), meets the accepted criterion of $>0.5$. The VE for the other dimensions is Atmosphere (0.37), Convenience (0.32), Facilities (0.39), Institutional (0.35), Merchandise (0.40), Promotion (0.38) and Service (0.34). This indicates that a greater amount of variance amongst the items is explained by measurement error rather than by the underlying dimension. The calculated CR for each dimension meets the set criteria of $>0.7$, that is Atmosphere (0.77), Convenience (0.77), Facilities (0.82), Institutional (0.76), Merchandise (0.84), Promotional (0.83), Sales personnel (0.84) and Service (0.80).

These results provided support for the convergent validity of the Sales personnel dimension that meets all the set criteria.

TABLE 11

Standardised residuals for Sales personnel dimension - Mall intercept study

\begin{tabular}{|c|c|c|c|c|c|}
\hline ITEMS & Item 43 & Item 44 & Item 45 & Item 46 & Item 47 \\
\hline Item 43 & - & & & & \\
\hline Item 44 & 4.70 & - & & & \\
\hline Item 45 & 0.20 & 2.40 & - & & \\
\hline Item 46 & -1.78 & -3.32 & -1.07 & - & \\
\hline Item 47 & -2.58 & -2.37 & -1.24 & 6.76 & - \\
\hline
\end{tabular}

\section{TABLE 12}

Standardised residuals for Service dimension - Mall intercept study

\begin{tabular}{|c|c|c|c|c|c|c|c|}
\hline ITEMS & Item 48 & Item 49 & Item 50 & Item 51 & Item 52 & Item 53 & Item 54 Item 55 \\
\hline Item 48 & - & & & & & & \\
\hline Item 49 & 6.55 & - & & & & & \\
\hline Item 50 & 5.75 & 3.06 & - & & & & \\
\hline Item 51 & -2.29 & -1.75 & -2.02 & - & & & \\
\hline Item 52 & -2.16 & -3.80 & -0.48 & 3.98 & - & & \\
\hline Item 53 & 1.18 & 2.75 & 0.71 & -1.06 & -1.56 & - & \\
\hline Item 54 & -4.18 & -3.53 & -3.00 & 1.23 & 3.12 & -0.96 & - \\
\hline Item 55 & -1.03 & -0.69 & -1.28 & -0.21 & -1.95 & 0.73 & 3.41 \\
\hline
\end{tabular}


TABLE 13

Model fit indices of CFA on the Simplified Model of Apparel Store Image - Mall intercept study

\begin{tabular}{lr}
\hline ABSOLUTE FIT MEASURES & \\
\hline Degrees of Freedom & 20 \\
Minimum Fit Function Chi-Square & 206.09 \\
& $\mathrm{p}<0.01$ \\
Root Mean Square Error of Approximation (RMSEA) & 0.14 \\
Standardised Root Mean Residual (RMR) & 0.064 \\
Goodness of Fit Index (GFI) & 0.91 \\
Adjusted Goodness of Fit (AGFI) & 0.83 \\
INCREMENTAL FIT MEASURES & \\
\hline Non-Normed Fit Index (NNFI) & 0.89 \\
Comparative Fit Index (CFI) & 0.92 \\
\hline
\end{tabular}

Results further suggested that the individual dimensions of Convenience, Facilities and Promotion meet two of the set criteria for convergent validity, namely completely standardised loadings and CR. It could be argued that this is indicative of marginal convergent validity, although all the prerequisites for convergent validity are not met. The Atmosphere, Institutional, Merchandise and Service dimensions, however, do not meet two of the set criteria and it can be concluded that these dimensions do not exhibit convergent validity. This provided further support for further purification of the store image scale through the deletion of the suggested items to improve convergent validity.

The VE of any two constructs and the squared correlation estimates between these constructs were investigated to support the discriminant validity of the scale. The interpretation of the squared correlation estimates has to be qualified by stating that the analysis for each dimension was based on a calculated composite score for all the items associated with the specific dimension. The squared correlation between Convenience and Facilities (0.35) was higher than the variance extracted for the Convenience dimension (0.32). Similarly, the squared correlation between Sales personnel and Service (0.38) exceeded the variance extracted for Service (0.33). These results provided evidence that the Convenience and Service dimensions lack discriminant validity and, therefore, implied that these dimensions are not statistically distinct from other dimensions included in the revised model of apparel store image (see Figure 2, Part 2). The deletion of the suggested items from the Convenience and Service dimensions will serve to further purify the store image scale, thereby improving discriminant validity. The results, however, provided support for the discriminant validity of the Atmosphere, Facilities, Institutional, Merchandise, Promotion and Sales personnel dimensions.

\section{Model fit - simplified model of apparel store image}

To assess the overall model fit, CFA was performed on the simplified model of apparel store image (see Figure 3, Part 2), based on the data obtained from the 55-item scale. Composite

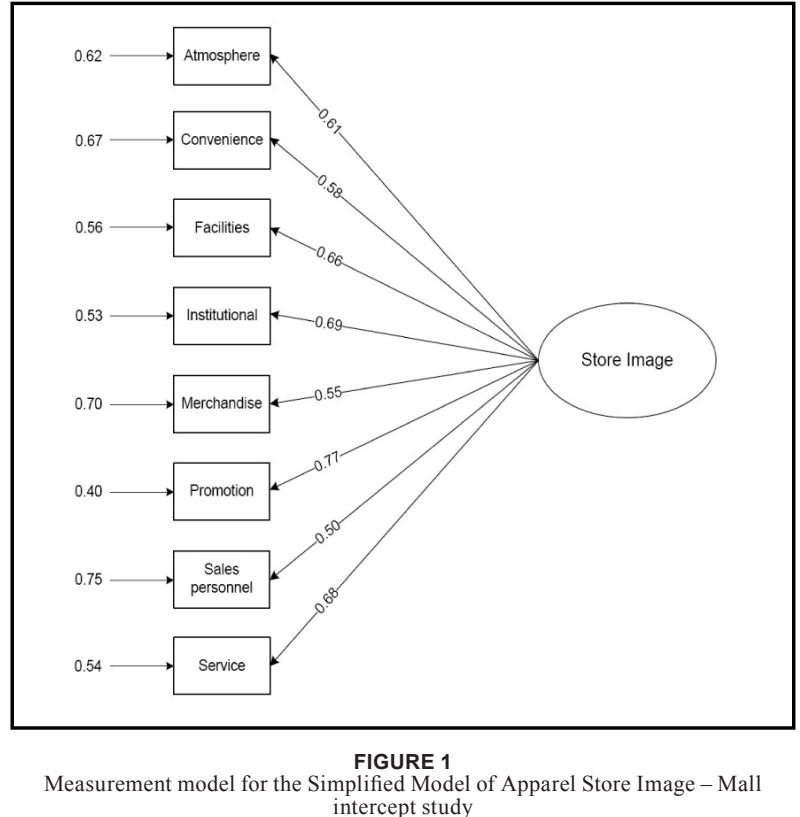

scores for the measurement items of each dimension were calculated and a single composite indicator was employed for each dimension, as per recommendations in the literature (Hair et al., 2006; Netemeyer et al., 2003). This was deemed necessary and appropriate since the large number of dimensions and their associated measurement items necessitated a sample size requirement outside the scope of this study. Maximum likelihood was used as method of estimation, since the indicators were no longer associated with a Likert-type scale. Table 13 provides a summary of the model fit indices.

The minimum fit function chi-square is significant, suggesting poor fit. Again, however, the chi-square statistic's sensitivity to multivariate normality and sample size should be highlighted (Diamantopoulos \& Sigauw, 2000). Root mean square error of approximation (RMSEA) falls outside the adopted criteria of $<0.08$ for acceptable fit. The standardised root mean residual (RMR) also falls outside the set criterion of $<0.05$. The goodnessof-fit index (GFI) value indicates good fit, since it is higher than 0.9. However, the adjusted goodness-of-fit index (AGFI) index does not meet this set criterion for good fit, namely $>0.9$. The comparative fit index (CFI) value exceeds 0.9 and indicates good fit. The non-normed fit index (NNFI) index does not meet the set criterion of $>0.9$ for good fit, although by only a small margin. From the results derived from the absolute fit measure, it can be concluded that the model does not exhibit acceptable fit. By implication, the implied model does not reproduce the observed model. The incremental fit measures indicate marginally acceptable fit. It can, therefore, be concluded that the implied model exhibits a better fit compared to the null model, assuming that all observed variables are uncorrelated.

TABLE 14

Summary of conclusions on model fit, reliability and validity of the individual dimensions and Simplified Model of Apparel Store Image

\begin{tabular}{|c|c|c|c|c|c|}
\hline MEASURE/DIMENSION & RELIABILITY & MODEL FIT & ITEM DELETION & CONVERGENT VALIDITY & DISCRIMINANT VALIDITY \\
\hline Atmosphere & Acceptable & Good & 6 & Acceptable & Good \\
\hline Convenience & Acceptable & Good & N/A & Acceptable & Poor \\
\hline Facilities & Acceptable & Acceptable & 15,19 & Acceptable & Good \\
\hline Institutional & Acceptable & Good & 26 & Poor & Good \\
\hline Merchandise & Acceptable & Poor & 30,33 & Poor & Good \\
\hline Promotion & Acceptable & Good & N/A & Acceptable & Good \\
\hline Sales personnel & Acceptable & Acceptable & 43 & Good & Good \\
\hline Service & Acceptable & Poor & $48,49,50$ & Acceptable & Poor \\
\hline Total model & Acceptable & Poor & $\mathrm{N} / \mathrm{A}$ & Acceptable & $\mathrm{N} / \mathrm{A}$ \\
\hline
\end{tabular}




\section{Convergent validity - simplified model of apparel store} image

Convergent validity was established as per the criteria adopted for the individual dimensions. The completely standardised loadings of the dimensions from the CFA performed on the simplified model of apparel store image are presented in Figure 1.

The completely standardised loadings ranged from 0.50 for Sales personnel to 0.77 for Promotion. The VE is recorded as 0.40 , which is lower than the cut-off value of $>0.5$. The CR is calculated at 0.89 . It can be concluded that the simplified model of apparel store image exhibits marginal convergent validity, since it met two of the set criteria. However, the results are still indicative of all measurements possibly not reflecting the same construct.

\section{CONCLUSION}

The results obtained from this phase of the study regarding the model fit, reliability and validity of the individual dimensions and the simplified model of apparel store image are summarised in Table 14.

Based on the results of this phase, the final model of apparel store image, presented in Figure 2, was developed. This model reflects the deletion of suggested items from the ASIS, which could serve to improve the model fit. An additional dimension was added, namely Store personnel interaction. Subdimensions that were not represented by items retained in the store image scale were excluded.
The final model of apparel store image and the results from the practical implementation of the store image scale led to a revised definition of store image as a complex, multidimensional construct based on the perception of tangible and intangible store attributes associated with nine dimensions, namely Atmosphere,Convenience,Facilities,Institutional,Merchandise, Promotion, Sales personnel appearance, Sales personnel interaction and Service. These dimensions are further divided into subdimensions that are underpinned by specific store attributes. Store image has a gestalt nature that is represented by the interaction between the salient tangible and intangible store attributes. The formation of store image relies on the perception of a store, which varies according to retailer, product and target market. By implication, store image is influenced by (1) the consumer's perception of a set of salient store attributes, (2) the importance the consumer places on the various store image dimensions, the subdimensions and the associated store attributes, as well as (3) the retailer's manipulation of these store attributes through strategic management.

\section{Limitations of the study (Part 1 to 3 )}

The boundaries and limitations of this series (in accordance with time, financial and feasibility constraints) are as follows:

- The proposed relationships in the theoretical model of store image and related consumer behaviour variables were of a conceptual nature (see Figure 1, Part 1). They were not investigated through empirical research in this study.

- To ensure that the scale length was acceptable for practical implementation, the ASIS could not be representative of all the subdimensions proposed in the revised model of

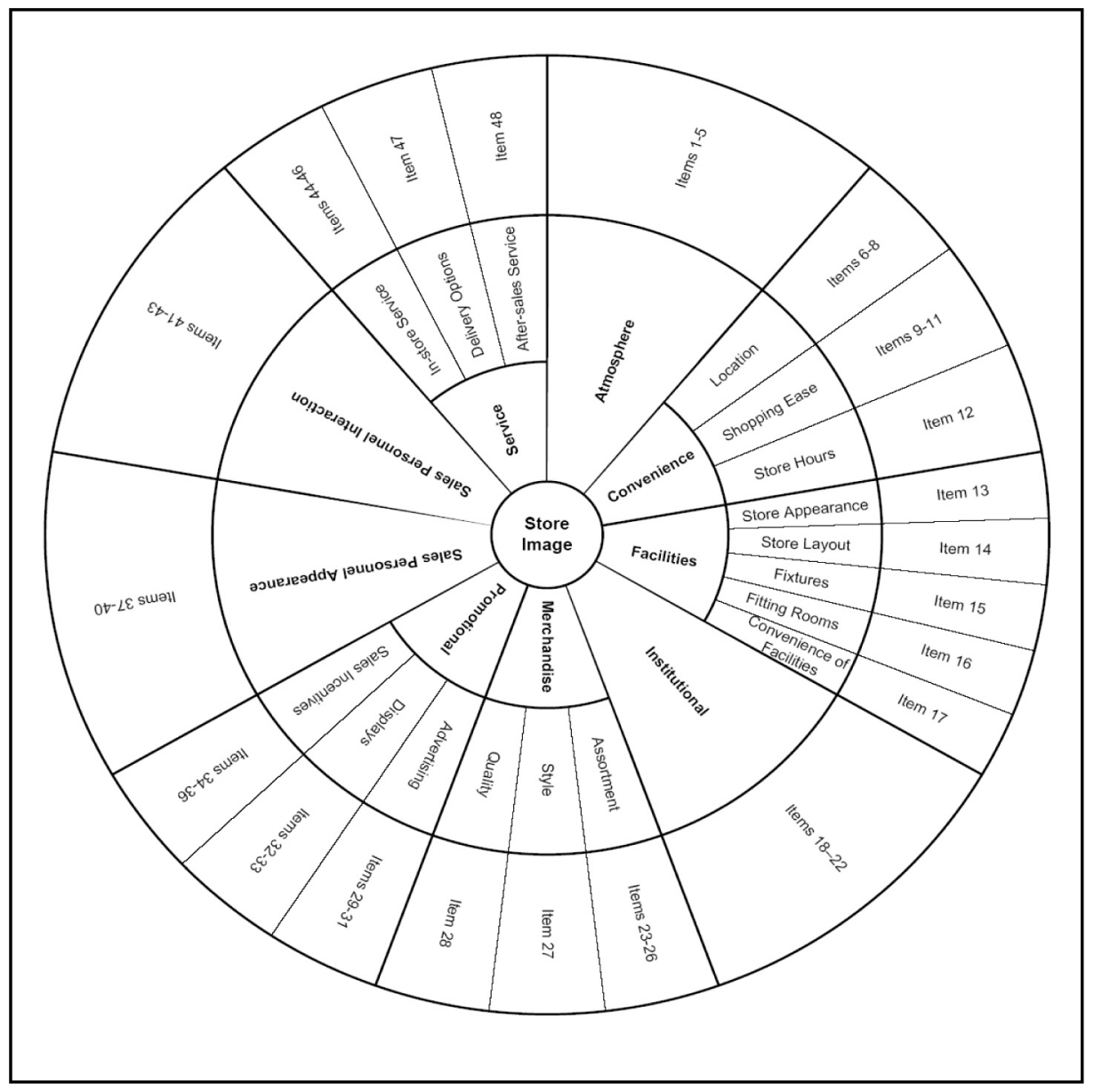

FIGURE 2

Final Model of Apparel Store Image 
apparel store image (see Figure 2, Part 2). This limited the insight into the underlying theoretical structure, specifically regarding the subdimensions of store image investigated in this study.

- The sample size requirements for the testing of the revised model of apparel store image, including the subdimensions, simultaneously through CFR fell outside the scope of this exploratory study. It could be argued that the testing of the comprehensive model would have provided additional insight.

- The study was limited to the geographical area of Cape Town and the store image scale was administered in English only.

However, these limitations were considered and addressed in the research design, statistical analysis and interpretation of the results. Therefore, the importance and relevance of the results of this exploratory research study continue to serve as a basis for future research.

\section{Suggestions for further research}

Based on the results of this three-part series, the following recommendations for future research could be formulated:

- The final model of store image (see Figure 2) should be tested. The further validation of the model will enhance the definition of store image by confirming the dimensions that underpin the construct.

- The refined ASIS should be further tested empirically. Research in this regard will serve to verify scale reliability and further establish scale validity.

- The ASIS should be employed to measure consumers' and retail management's perception of store image. This will assist in ensuring that there is congruency between consumers and retail management regarding the perceived importance of store image dimensions.

- The ASIS could be adapted to measure consumers' perception of store image, i.e. positive or negative perception of store image. This will enable insight into consumers' actual perception of a store's image. It could further be adapted to measure consumers' ideal of store image, i.e. what consumers would like the store image to be.

- The valence of the various store image dimensions (as contributing to the formation of the total store image) could be established.

- The relationship between apparel store image and corporate and retail store branding warrants further investigation through empirical research. This will enhance the contextual framework for the study of store image.

- The proposed conceptual theoretical model of the relationship between store image and related consumer behaviour variables could be tested empirically. Thus, further insight will be gained into the store image construct domain.

- The ASIS should be applied in other product areas, as well as in different geographical areas and sample populations.

\section{FINAL REMARKS}

Corporate and retail store branding strategies empower retailers to successfully differentiate themselves from their competitors in the complex, competitive apparel retail environment. The retail store is the culmination of these differentiation strategies where consumers actively interact with the corporate and retail store brand. Thus, store image becomes an integral component of corporate and retail store branding. By implication, an understanding of the perceived importance that consumers place on the dimensions and subdimensions of apparel store image becomes vital for retail differentiation. This exploratory study, reported in three papers, provides insight into what constitutes the underlying structure of apparel store image through the final model of apparel store image. An ASIS to measure the perceived importance of the dimensions of apparel store image was developed. The integration and manipulation of these salient dimensions in the corporate and retail store brand strategies will be the key to retail differentiation and, ultimately, success and survival. Store image research needs to move beyond isolated research findings. These articles attempted to significantly contribute in this regard.

\section{REFERENCES}

Bellenger, D.N., Robertson, D.H. \& Greenberg, B.A. (1977). Shopping center patronage motives. Journal of Retailing, 53(2), 29-38.

Bellizzi, J.S., Crowley, A.E. \& Hasty, R.W. (1983). The effects of color in store design. Journal of Retailing, 59(1), 21-45.

Cary, R.T. \& Zylla, J.M. (1981). Fabric specialty stores: consumer dissatisfaction with selected in-store attributes. Journal of Consumer Studies and Home Economics, 5, 69-78.

Chowdhary, U. (1999). Retail store attributes, fashion leadership and older consumers. Journal of Fashion Marketing and Management, 3(2), 126-132.

Dabholkar, P.A., Thorpe, D.I. \& Rentz, J.O. (1995). A measure of service quality for retail stores: scale development and validation. Journal of the Academy of Marketing Science, 24(1), 3-16.

Dhurup, M., Venter, P.F. \& Oosthuyzen, A. (2005). A factor analytical service quality measurement scale for supermarkets in South Africa. South African Journal of Economic and Management Science, 8(2), 140-153.

Diamantopoulos, A. \& Sigauw, J.A. (2000). Introducing LISREL: a guide for the uninitiated. London: Sage Publications.

Dillon, W.R., Madden, T.J. \& Firtle, N.H. (1994). Marketing research in a marketing environment (3rd Ed.). Burr Ridge, Illinois: Irwin.

Du Preez, R. (2001). Female apparel shopping behaviour within a multi-cultural consumer society: variables, market segments, profiles and implications. Unpublished doctoral thesis. Stellenbosch: Stellenbosch University.

Erdem, O., Oumlil, A.B. \& Tuncalp, S. (1999). Consumer values and the importance of store attributes. International Journal of Retail and Distribution Management, 27(4), 137-144.

Grace, D. \& O'Cass, A. (2005). An examination of the antecedents of repatronage intentions across different store formats. Journal of Retailing and Consumer Services, 12(4), 227-243.

Hair, J.F., Black, W.C., Babin, B.J., Anderson, R.E. \& Tatham, R.L. (2006). Multivariate data analysis (6th Ed.). Upper Saddle River: Pearson/Prentice Hall.

Hansen, R.A. \& Deutscher, T. (1977-1978). An empirical investigation of attribute importance in retail store selection. Journal of Retailing, 53(4):59-72.

Huddleston, P., Ford, I. \& Mahoney, M.Y. (1990). The relationship between importance of retail store attributes and lifestyle of mature female consumers. Journal of Consumer Studies and Home Economics, 14, 71-85.

Janse van Noordwyk, H.S. (2002). Perceived importance of retail store image attributes to the female large-size apparel consumer in a multicultural society. Unpublished master's thesis. Stellenbosch: Stellenbosch University.

Jöreskog, K. \& Sörbom, D. (2006). LISREL 8.8. Chicago, IL: Scientific Software International Inc.

Joyce, M.L. \& Lambert, D.R. (1996). Memories of the way stores were and retail store image. International Journal of Retail and Distribution Management, 24(1), 24-33.

Kim, J.O. \& Jin, B. (2001). Korean consumers' patronage of discount stores: domestic vs. multinational discount store shoppers' profiles. Journal of Consumer Marketing, 18(3), 236-255. 
Kleinhans, E.H. (2003). Black female student consumers' perception of clothing store image attributes. Unpublished master's thesis. Stellenbosch: Stellenbosch University.

Ko, E. \& Kincade, D.H. (1997). The impact of quick response technologies on retail store attributes. International Journal of Retail and Distribution Management, 25(2/3), 90-99.

Koo, D. (2003). Inter-relationships among store images, store satisfaction, and store loyalty among Korea Discount Retail patrons. Asia Pacific Journal of Marketing and Logistics, 15(4), $42-71$.

Kotler, P. (1973-1974). Atmospherics as a marketing tool. Journal of Retailing, 49(4), 48-55.

Lee, M. \& Johnson, K.K.P. (1997). Customer expectations for service at apparel retail outlets. Journal of Family and Consumer Sciences, Winter, 26-30.

Lindquist, J.D. (1974-1975). Meaning of image. Journal of Retailing, 50(4), 29-38.

Loudon, D.L. \& Della Bitta, A.H. (1993). Consumer behavior concepts and applications (4th Ed.). New York: McGraw-Hill.

Lumpkin, J.R., Greenberg, B.A. \& Goldstucker, J.L. (1985). Marketplace needs of the elderly: determinant attributes and store choice. Journal of Retailing, 61(2), 75-105.

Marks, R.B. (1976). Operationalizing the concept of store image. Journal of Retailing, 52(3), 37-46.

Moye, L.N. \& Kincade, D.H. (2002). Influence of usage situations and consumer shopping orientations on the importance of retail store environment. International Review of Retail, Distribution and Consumer Research, 12(1), 59-79.

Netemeyer, R.G., Bearden, W.O. \& Sharma, S. (2003). Scaling procedures: issues and applications. Thousand Oaks: Sage Publications.
Odekerken-Schröder, G., De Wulf, K., Kasper, H., Kleijnen, M., Hoekstra, J. \& Commandeur, H. (2001). The impact of quality on store loyalty: a contingency approach. Total Quality Management, 12(3), 307-322.

Parasuraman, A.,Zeithaml, V.A. \& Berry, L.L. (1988).SERVOUAL: a multi-item scale for measuring consumer perceptions of service quality. Journal of Retailing, 64(1), 12-37.

StatSoft Inc. (2007). STATISTICA 8.0. [computer software] www. statsoft.com.

Sullivan, P., Savitt, R., Zheng, Y. \& Cui, Y. (2002). Rural shoppers: who gets their apparel dollars? Journal of Fashion Marketing and Management, 6(4), 363-380.

Terblanché, N.S. \& Boshoff, C. (2004). The in-store shopping experience: a comparative study of supermarket and clothing store customers. South African Journal of Business Management, 35(4), 1-9.

Thang, D.C.L. \& Tan, B.L.B. (2003). Linking consumer perception to preference of retail stores: an empirical assessment of the multi-attributes of store image. Journal of Retailing and Consumer Services, 10(4), 193-200.

Thompson, K.E. \& Chen, Y.L. (1998). Retail store image: a meansend approach. Journal of Marketing Practice, 4(6), 161-173.

Venter, P.F. \& Dhurup, M. (2005). Consumer perceptions of supermarket service quality: scale development and validation. South African Journal of Economic and Management Sciences, 4, 424-436.

Wong, G.K.M. \& Yu, L. (2003). Consumers' perception of store image of joint venture shopping centres: first-tier versus second-tier cities in China. Journal of Retailing and Consumer Services, 10(2), 61-70.

Wong, J.K. \& Teas, R.K. (2001). A test of the stability of retail store image mapping based on multi-entity scaling data. Journal of Retailing and Consumer Services, 8(2), 61-70. 